\title{
2020 Proceedings
}

\author{
The Digitization of a Nationally Significant Historic Dress Using 3D Apparel \\ Simulation Software
}

Nicole Villarreal, Anne Porterfield, Cynthia L. Istook

Wilson College of Textiles, NC State University

Keywords: CLO, 3D apparel simulation, historic garments

The use of 3D apparel simulation software in the fashion industry aids in the prototyping of garments to reduce cost and speed up the product development process (Ancutiené, 2014). This technology can also be used as a tool to digitize historic costume. It allows for permanent online display and access (Zeng, 1999), helps with the dissemination of information (Clough, 2013), increases audience engagement (Hume, 2017; Martin, Jushchyshyn, \& Caulfied-Sriklad, 2016), and is useful as a marketing tool to draw visitors to online and onsite exhibitions (Johansen, 2010; Pallud \& Straub, 2012).

For this research, a silk chiffon and lace evening gown (ca 1920-1930) worn by suffragist Carrie Lane Chapman Catt (1859-1947) was simulated using CLO 3D apparel simulation software. A reproduction of the dress is displayed at the National Nineteenth Amendment Society in Charles City, IA with the original stored at the same location. The 3D simulation was developed based on photographs, a research paper with detailed descriptions of the dress and construction techniques used, and a pattern diagram based on the original dress measurements (Jacob, 2006). The objective was to investigate the tools needed for 3D digitization and visualization when digitizing historic costume, and the decision-making process that is involved. Here, the most important steps in the digitization and visualization process will be highlighted.

The garment was first evaluated to determine whether it was suitable for 3D digitization. Criteria were fit, ease of construction, and materials used. Since the fit of the gown was loose and free-flowing, construction was not overly complicated, and materials were readily available in the CLO fabric library (silk chiffon and crepe de Chine), the garment was deemed suitable for digitization. An adjustable CLO avatar was used to mount the gown. Because of the loose fit and lack of corseting, there was no need to adjust the avatar's measurements. The avatar was later hidden so as not to withdraw attention from the simulated garment.

The virtual sewing process was characterized by decision-making in the construction sequence. The dress lining was constructed first, after which the dress was constructed separately and layered over the lining. The pleating on the shoulders had to be done before the rest of the gown could be sewn together. As the garment was constructed, attention had to be paid to the layering sequence so that all pieces showed, and none would get twisted.

Assigning the fabric characteristics highlighted the iterative nature of the visualization process, and the constant need for evaluation. While CLO has set parameters for 
materials, colors, and the physical properties of fabrics, this information is generally not available for historic garments. As a result, the information entered is subjective and the end results depend on the visual evaluation of the creator of the 3D simulation.

The embellishments on the chiffon gown were minimal, except for the lace pattern on the inserts and handkerchief skirt. This was the only step in the visualization process were a third-party software (Adobe Photoshop) was needed to recreate the lace pattern. It was found that importing patterns and textures from other programs tends to slow down the simulation speed of the software.

The final rendering was time-consuming (five hours) and required a CPU with a specialized graphics card in the hardware. Again, setting up the background for the final rendering (lighting, resolution, et cetera) is a subjective and iterative process. Figure 1 shows a photograph of the front of the gown (A), the front of the 3D simulated gown (B), a photograph of the back of the gown back (C), and the back of the 3D simulated gown (D).

\section{Figure 1}

Comparison of photographs and $3 D$ simulations of historic dress: front $(A, B)$ and back $(C, D)$
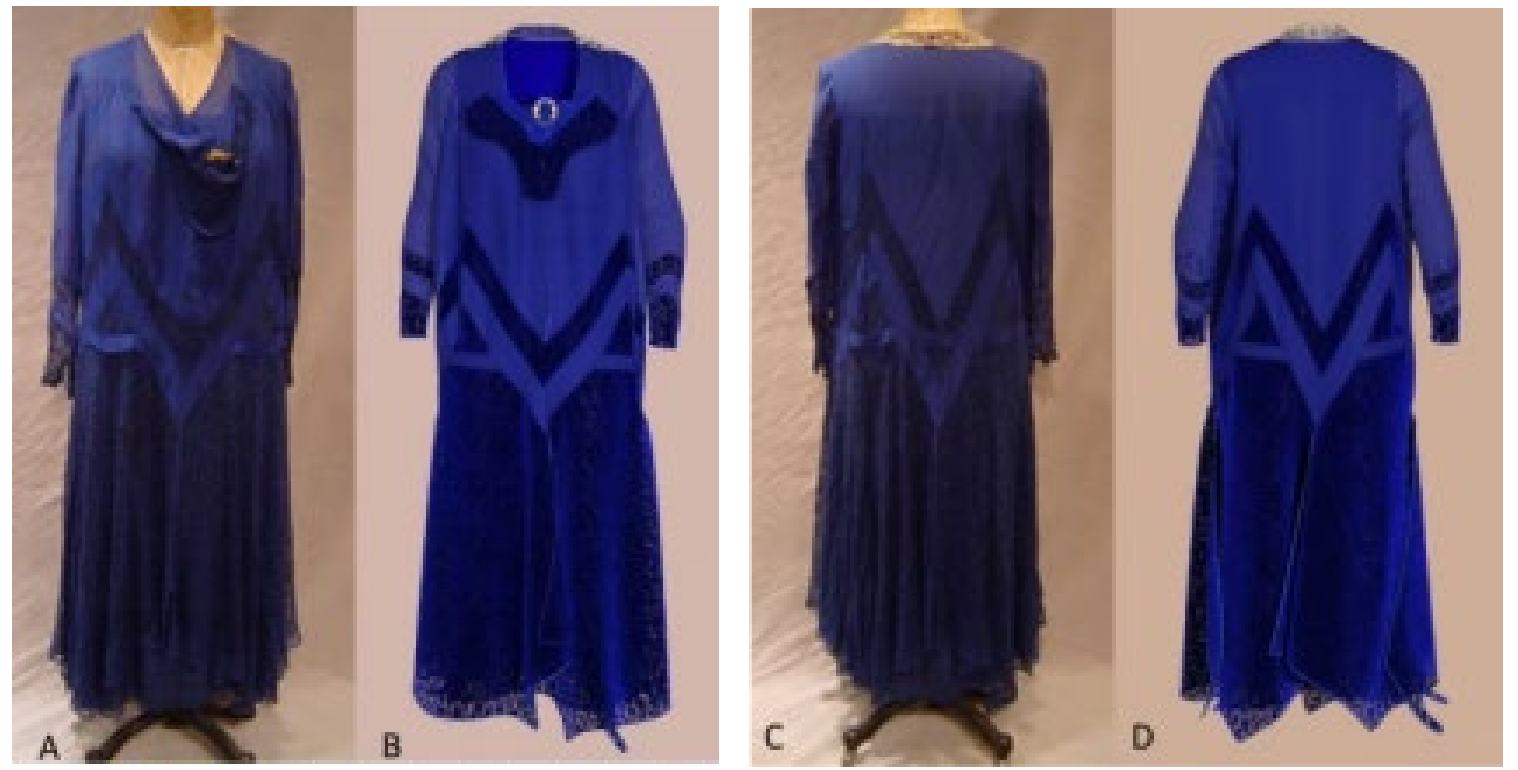

Note. Photographs A and C from The Costar Archives (n.d.),

http://costumes.unc.edu/costar/view/Costar/garment.jsp?id=4168. Copyright The Consolidated Clothing Archive. Reprinted with permission.

Simulations B and C. Copyright 2019 by Nicole Villarreal. 
This project established that digitization of historic costume using 3D apparel simulation software is feasible and that it can be successful. However, the visualization process of historic garments differs significantly from the development of virtual prototypes, and it requires knowledge of historic costume and mounting techniques to create a historically correct representation. It is characterized by a continuous decision-making process that is somewhat subjective, and which affects the overall outcome of the 3D simulation. 


\section{References}

Ancutiené, K. (2014). Comparative analysis of real and virtual garment fit/Studiu comparativ privind probarea reala si virtuala a articolelor de îmbracaminte. Industria Textila, 65(3), 158.

Clough, G.W. (2013). Best of both worlds: Museums, libraries, and archives in a digital age. Washington, DC: Smithsonian Institution.

Hume, S. (2017). Curation in practice. In I. Mida (Ed.). Everyone their own curator: Professionalism and authority in the digital age. Scholars' Roundtable, 2016 CSA Symposium. Dress (43) 1, 45-61.

Jacob, J. (2006). Silk chiffon and lace evening gown. Retrieved from http://costumes.unc.edu/costar/view/Costar/public/Spage.jsp?spageId=257

Johansen, K. (2010). Digital costume display. In Textile Society of America Symposium Proceedings. Paper 26. Martin, K., Jushchyshyn, N., \& Caulfield-Sriklad, D. (2016). Creating, exhibiting and distributing new media for historic fashion: The Drexel Digital Museum Project. From SIGradI 2016, XX Congress of the Iberoamerican Society of Digital Graphics, Buenos Aires, Argentina, 931-937.

Pallud, J. \& Straub, D.W. (2012). Effective website design for experience-influenced environments: The case of high culture museums. Information \& Management, 51, 359373.

Zeng, M.L. (1999). Metadata elements for object description and representation: A case report from a digitized historical fashion collection project. Journal of the American Society for Information Science, 50(13), 1193-1208. 